\title{
INVESTIMENTO SOCIAL PRIVADO EM EDUCAÇÃO: DESMONTE DO CARÁTER PÚBLICO DA EDUCAÇÃO
}

\author{
Vania Cardoso Motta \\ Universidade Federal do Rio de Janeiro - UFRJ
}

\section{RESUMO}

Este artigo apresenta, sinteticamente, os resultados parciais de pesquisa ${ }^{1}$ sobre a questão do investimento social privado em educação. Situada no âmbito dos debates sobre trabalhoeducação, a análise tomou como referência a teoria social crítica, à luz da "Lei geral da acumulação do capital", tendo em vista os segmentos da superpopulação relativa, da dinâmica de correlação de forças que insere o processo pedagógico de hegemonia, em seu conteúdo e forma, e como se estabelece a união pessoal neste bloco de poder. Indica que a abordagem dos setores empresariais em relação à educação está relacionada ao aumento da produtividade e à possibilidade de explorar o mercado de consumo de serviços em educação; como também, enfatiza o enfrentamento da "questão social". Diante da presença organizada do setor empresarial nos últimos encaminhamentos de políticas públicas da educação brasileira e da forma privatista de intervenção nas redes públicas de educação básica e em aparelhos do Estado, nossa hipótese é que está em curso o desmonte do caráter público de educação.

Palavras-chave: trabalho-educação; investimento social privado em educação; políticas públicas da educação brasileira.

\section{PRIVATE SOCIAL INVESTMENT IN EDUCATION: DISMANTLING OF THE PUBLIC CHARACTER OF EDUCATION.}

\begin{abstract}
This article presents, in short, the partial search results on the issue of private social investment in education. Situated in the context of discussions on work-education, the analysis took as a reference to critical social theory in the light of the "general law of capital accumulation", in view of the segments of the relative overpopulation, the dynamic correlation of forces that enter the pedagogical process of hegemony in its content and form, and how to establish the personal union in this power block. It indicates that the approach of the business sectors in relation to education is related to increased productivity and the possibility to exploit the consumer market services in education; but also emphasizes the confrontation of the "social question". Faced with the organized presence of the business sector in recent public policy referrals of Brazilian education and privatized form of intervention at public basic education and state apparatus, our hypothesis is that there is an ongoing dismantling of the public character of education.

Keywords: work-education; private social investment in education; public policies of Brazilian education.
\end{abstract}




\section{Introdução}

Ampliar a participação de aparelhos "privados" de hegemonia nas ações e nas definições de políticas públicas tem sido uma tendência dos últimos governos. As parcerias público-privadas foram apresentadas pelo governo Lula $^{2}$, e mantidas no governo de Dilma Rousseff, como uma saída colaborativa de investimento em infraestrutura junto ao setor empresarial, tendo em vista aumentar a capacidade produtiva e a competitividade dos setores produtivos do país. E, no âmbito social, como mecanismo de amenizar as consequências das políticas macroeconômicas de cunho neoliberal, supostamente assegurando o controle do déficit fiscal e a governabilidade.

Sem entrar no mérito da continuidade ou ruptura de governos, pelo menos de forma linear, é possível constatar que na esfera social, de certa forma, tais "parcerias" vêm se realizando desde o governo de Cardoso, regulamentadas por instrumentos normativos criados no processo da "reforma"3 administrativa gerencial pública que configurou o Estado gerencial. ${ }^{4}$ Destacamos, neste processo, a regulamentação de entidades de direito privado, de interesse social e utilidade pública ${ }^{5}$ que foram criadas com a finalidade de absorver atividades públicas nas áreas de educação, pesquisa científica, desenvolvimento tecnológico, meio ambiente, cultura, saúde e esporte, definidas como "serviços não exclusivos do Estado". Foi nesse quadro político e social que surgiram as expressões, primeiramente, responsabilidade social corporativa e mais tarde investimento social privado.

Especificamente no âmbito da educação básica pública, observamos que o encaminhamento das parcerias público-privadas com o setor empresarial vem sendo realizado tanto para finalidades de mercantilização, o interesse imediato de acumular capital por meio dos novos nichos de mercado que se abrem na área, como para mercadorização, no sentido da natureza das relações sociais de produção capitalista, onde tudo se transforma em mercadoria. E traz elementos de recomposição da superpopulação relativa em dois movimentos: qualificando a força de trabalho em potencial e educando para se adaptar às incertezas do mundo do trabalho mundializado. Nossa hipótese é a de que trata-se de uma tendência política de desmantelando o caráter público da educação escolar.

Trabalhando com o referencial teórico-metodológico da teoria social crítica, buscamos refletir a questão do investimento social privado em educação à luz da Lei geral, absoluta, da acumulação do capital, em Marx (2002), tendo em vista os segmentos da superpopulação relativa, e pautar a dinâmica de correlação de forças que insere o processo pedagógico de hegemonia, em seu conteúdo e forma (GRAMSCI, 2000), e como se estabelece a união pessoal (LÊNIN, 2005) neste bloco de poder.

Indicamos, com base em pesquisas anteriores sobre o atual contexto, que a abordagem dos setores empresariais em relação à educação está relacionada tanto ao insumo de produção - uma mercadoria que eleva a capacidade produtiva e a qualidade do produto (sob as bases da teoria do capital humano) - e pela possibilidade de acumular riqueza, tendo em vista o potencial do mercado de consumo de serviços em educação. Como também, enfatiza o necessário vínculo entre crescimento econômico e redução da pobreza, como forma de enfrentamento da "questão social" (sob as bases da teoria do capital social) (MOTTA, 2012).

Diante da crescente e ativa presença do setor empresarial na educação, perguntamos: Como surgiram e são definidas as expressões responsabilidade social corporativa e investimento social privado? Por que a concepção de responsabilidade social vem sendo substituída pela expressão investimento social privado? E como essa forma de 
intervenção vem se realizando na esfera da educação básica pública? Nosso objetivo é apresentar, sinteticamente, os resultados parciais de nossa pesquisa sobre os investimentos sociais privados em educação que compõem os arranjos de desenvolvimento da educação referenciados no Parecer CEB/CNE n ${ }^{\circ}$ 9/2011. ${ }^{7}$

\section{Responsabilidade social corporativa e investimento social privado}

Em levantamento de estudos sobre o tema, identificamos que as expressões responsabilidade social corporativa e investimento social privado ou investimento social corporativo surgiram nos anos 1990 (NOGUEIRA e SCHOMMER, 2009; KON, 2013). Embora tenham surgido no mesmo período e possuírem o mesmo teor fim - "diferenciar de formas mais tradicionais de filantropia" (MONTEIRO; KISIL; WOODS, 2011, p.1) vimos que possuem enfoques diferenciados: responsabilidade social corporativa enfatiza a atitude do empresário (GIFE, 2003) e investimento social privado faz referência às formas de investir; o que não exclui determinados comportamentos (NOGUEIRA e SCHOMMER, 2009). E que a expressão responsabilidade social corporativa, gradativamente, cede lugar para investimento social privado.

Segundo Kon (2013), a expressão responsabilidade social surgiu pela necessidade de se construir uma "nova cultura organizacional", tendo em vista questões ambientais, porém não limitadas à preservação da natureza, mas também aos problemas sociais. Isto é, a proposta de uma "nova cultura organizacional" surge na perspectiva do "desenvolvimento socioeconômico sustentável" - uma forma de "conciliar o desenvolvimento econômico com a preservação ambiental e a diminuição da pobreza e da má distribuição de recursos no mundo" (p.49). Para a autora, a questão central da "nova cultura organizacional" partiu do fato de que:

[...] por um lado, observa-se riqueza e melhora do bem-estar em sociedades específicas em relação a padrões de períodos anteriores da história mundial. Por outro lado, a miséria, a degradação ambiental e a poluição aumentam dia a dia (KON, 2013, p.49).

Kon (2013) ressalta que essa "nova cultura organizacional" deveria se realizar por meio de um amplo diálogo entre demais empresas, organismos internacionais, regionais e multilaterais, organizações não-governamentais, sindicatos, entre outras organizações da sociedade civil. O enfoque moral e cultural é o elemento enfatizado e que permeia a expressão responsabilidade social corporativa.

Em pesquisas anteriores, identificamos num conjunto de relatórios de organismos internacionais (BIRD, BID, ONU, UNESCO e CEPAL ${ }^{8}$ ), entre 1995-2000, preocupações com os "desequilíbrios" causados pelo modelo de econômico neoliberal nos anos finais do século XX. No Relatório sobre o Desenvolvimento Mundial 2000/2001: Luta contra a Pobreza do Banco Mundial (2000. Apud. MOTTA, 2012a), por exemplo, expressa essa preocupação da seguinte forma: "Pobreza em meio à abundância é o maior desafio que o mundo enfrenta" (p. 203).

Nesse período, mais especificamente no Fórum Econômico Mundial, Davos, em 1999, foi anunciado o "Pacto Global das Nações Unidas", lançado oficialmente por Kofi Annan, em julho de 2000, em Nova Iorque (expressão culminante dessa frente de ajuste ético-político, buscando "atribuir uma face mais humana ao capital", MOTTA, 2012); e são traçados os Objetivos de Desenvolvimento do Milênio (ODM). O objetivo central é 
formar uma rede constituída de vários setores da sociedade (governos, empresários, organizações não-governamentais, sindicatos e academia), em prol da harmonização do sistema. Neste, os empresários são vistos como protagonistas centrais na adoção de políticas de responsabilidade social e sustentabilidade, tendo em vista o desenvolvimento de um mercado global mais inclusivo e sustentável e constituir uma dimensão social à acumulação do capital (INSTITUTO ETHOS, 2002; ONU, s/d). ${ }^{9}$

Constatamos, ainda, que a proposta de Giddens da terceira via ${ }^{10}$ - "criar um consenso internacional de centro-esquerda para o século XXI" (Giddens, 2001, Apud MOTTA, 2012, p.77 ) - já ressaltava a cultura empresarial: "Uma sociedade que não estimula a cultura empresarial não pode gerar a energia econômica que provém das ideias mais criativas" (Idem, p.80; grifo nosso). Os empresários, para o autor, "são inovadores, porque reconhecem as oportunidades que os outros perdem ou assumem os riscos que os outros rejeitam, ou ambos" (idem). Nessa perspectiva, Giddens aponta que tanto os empresários sociais, cívicos ou aqueles que trabalham diretamente no mercado são importantes, "uma vez que o impulso e a criatividade necessários no setor público e na sociedade civil são os mesmos de que se precisa na esfera econômica" (Ibidem, p.79). Proposta que teve grande repercussão nos anos 1990 e que revela aproximação com Joseph Schumpeter (1883-1950), ${ }^{11}$ em sua teoria do desenvolvimento que traz o conceito "destruição criativa". Para Schumpeter (1982), a conduta própria de empresários empreendedores de enfrentar riscos e a inovar permanentemente o processo produtivo, num fluxo contínuo de destruição e criação de novos produtos para o mercado, é a força propulsora de acumulação de riqueza e motor de desenvolvimento.

Nesse sentido, podemos constatar que a "nova cultura organizacional" está em conformidade com os organismos internacionais e com a tendência de buscar outras vias para amenizar a "questão social".

Encontramos a definição de investimento social privado no relatório do Grupo de Institutos, Fundações e Empresas (GIFE) de 2007 (Apud. NOGUEIRA e SCHOMMER, 2009) ${ }^{12}$ como: "repasse voluntário de recursos privados de forma planejada, monitorada e sistemática para projetos sociais, ambientais e culturais de interesse público" (p. 3). Explica:

É possível entender essa definição como a reunião de três grandes aspectos definidores do investimento social:

1. a origem dos recursos: privada e voluntária (o que a diferenciaria de outros tipos de investimento, de origem compulsória, como parte dos recursos do Sistema $\mathrm{S}$ );

2. a forma de atuação: planejada, monitorada e sistemática (fundamentalmente, buscando resultados, em contraposição às práticas bem-intencionadas mais voluntaristas, amadoras e supostamente ineficientes da caridade tradicional);

3. a finalidade: projetos sociais, ambientais e culturais de interesse público (colocando-o acima de interesses privados que a empresa ou o filantropo possam ter ao investir no social) (NOGUEIRA e SCHOMMER, 2009, p.3)

Segundo essa definição, o investimento social privado se refere à aplicação de recursos financeiros, mas com exigência de retornos, de resultados (não financeiros, pois não pode ter finalidades de mercantilização); está relacionado à atitude privada e voluntária do empresário em doar/investir seus recursos em projetos sociais, porém de forma a obter resultados concretos. Inclui elementos de responsabilidade social, enquanto uma conduta 
neofilantrópica voltada para amenizar a "questão social", porém o investimento social privado inclui uma determinada forma de gerenciamento do investimento revestida do caráter empreendedor do empresário - retorno, resultados, que insere também atitude inovadora (DEBONI, 2013).

No artigo de Kon (2013), Jeffrey Sachs ${ }^{13}$ é citado como o autor que apresenta "Análises consistentes sobre o papel das empresas na construção de uma sociedade menos desigual e na busca do desenvolvimento sustentável” (p. 52). E destaca que:

Sachs (2005) desenvolve também a ideia de que as empresas têm um papel social transformador na atitude dos indivíduos, tornando-os consumidores mais bem informados e exigentes quanto a produtos e serviços. Assim, eles se convertem em cidadãos mais conscientes das necessidades de suas comunidades, passando, consequentemente, a reivindicar o cumprimento das responsabilidades das empresas para seu desenvolvimento (Idem, grifo nosso).

Sachs foi um dos difundores da ideia de "mercado inclusivo". A concepção de "mercado inclusivo" consta em relatórios da ONU ${ }^{14}$, onde discorre sobre "o poder das empresas a serviços dos pobres" e os bons negócios que essa aproximação pode render. Consideramos que é nessa perspectiva que a concepção de investimento social privado começa a ter mais força ${ }^{15}$ e que foram criadas as condições favoráveis para privilegiar a participação dos empresários nas definições de políticas públicas. A nosso ver, a "união pessoal", conceito trabalhado por Lênin $(2005$, p. 42) para indicar a relação orgânica entre o setor industrial com o financeiro e entre estes com os governos na fase "superior do capital" - o Imperialismo -, torna-se mais explícita e diretamente ativa na atual conjuntura.

No Brasil, o GIFE é um dos organizadores e orientadores dos empresários associados em relação ao investimento social privado, estimulando o caráter empreendedor e inovador. Em 2002, lançou o "Guia GIFE sobre Investimento Social Privado - Como Iniciar um Programa de Ação Social na sua Empresa" e em 2003, editou um "guia" voltado para "Investimento Social Privado em Educação". Neste último, apresenta "recomendações que devem ser observadas quando da concepção de um projeto de investimento social privado em educação" (p. 37; grifo nosso), a fim de consolidar o investimento e obter escala.

O Censo GIFE/2009, que inclui o mapeamento dos investimentos sociais privados e é elaborado a cada dois anos, identificou que a educação é a área prioritária de investimento: "Em 2007, 80 associados - de uma base de 101 organizações - investiram R \$ 1,15 bilhões nessa área". ${ }^{16}$ No Censo GIFE 2011/2012 ${ }^{17}$ são cerca de 140 associados e a pesquisa foi composta por 100 entidades (13 empresas e 87 institutos ou fundações), com aporte anual da ordem de R \$ 2,2 bilhões. Segundo o Censo GIFE 2011/2012: "Educação continua sendo o principal tema da Rede GIFE. Ela não apenas se mantém em primeiro lugar desde o primeiro Censo, como também apresenta um crescimento de $2 \%$ em relação a $2011 "$ (p. 7). ${ }^{18}$ Ainda:

As ações executadas ou financiadas pelos associados GIFE em educação envolvem, na maioria dos casos, a capacitação de professores. $65 \%$ das empresas, associações e fundações que responderam a este detalhamento desenvolvem tal atividade, provavelmente com vistas a contribuir para a melhoria na qualidade da rede pública de ensino. A doação de livros e 
materiais didáticos está igualmente associada a esta intenção, e é realizada por $43 \%$ dos associados. A oferta de atividades de reforço escolar também se revela significativa dentre os respondentes, com $46 \%$ de organizações atuando nesta frente. Investimentos em construção, reforma ou manutenção de escolas são feitos por apenas $17 \%$ das organizações (GIFE, 2012, p. 39).

O Censo GIFE 2011-2012 revela que a prioridade de investir na Educação, em particular na educação pública, é focada nos aspectos pedagógicos. O que nos dá elementos para averiguar a influência da referida "nova cultura organizacional" nos espaços escolares, que se pauta nas atitudes empresariais voluntárias, empreendedoras (investimento com resultado) e inovadoras para enfrentar questões seculares que perduram até hoje.

Cabe observar que no $8^{\circ}$ Congresso GIFE, São Paulo, 2014, com a temática "Por um Investimento Social Transformador", foi enfatizada a necessidade de definir metas claras em temas como: "acabar com a pobreza; promover o crescimento sustentável e empregos; educação para todos; proteção dos direitos humanos; saúde para todos; agricultura sustentável; [...] e boa governança". ${ }^{19}$ Isso pode revelar que os resultados esperados não estão sendo bons e talvez a questão da precária infraestrutura das redes públicas de ensino sejam impeditivas, como veremos adiante. E importante socializar que o tema do $9^{\circ}$ Congresso GIFE, a ser realizado neste ano de 2016, é "O sentido público do investimento social privado".

\section{Investimento Social Privado em Educação}

Temos clareza de que, historicamente, as definições de políticas, organização e diretrizes básicas da educação brasileira sempre estiveram relacionadas à esfera econômica e ajustadas aos ciclos de expansão do capitalismo mundial e local, como expressão das correlações de forças internas (a exemplo dos Pioneiros da Educação (1932) e da criação do Serviço Nacional de Aprendizagem Industrial (SENAI), pelos decretos-lei 4.048 e 4.936, em 1942). Conforme conjuntura histórica, as bases ideológicas conservadoras ${ }^{20}$ das "reformas" educacionais se fundaram ora como fator de modernização, ora como motor de desenvolvimento econômico e social e de elevação da produtividade, ora como mecanismo de aumento da capacidade competitiva no mercado internacional.

Do mesmo modo, tais "reformas" estiveram articuladas à "questão social": ora como superação da mentalidade atrasada das camadas populares que estavam pondo em risco o processo civilizatório da, então, nascente sociedade industrial, ofertando-lhes a instrução básica (ler, escrever e contar) ${ }^{21}$, ora como mecanismo de equalização social, de alívio à pobreza e de segurança nacional e internacional ${ }^{22}$, ora como ameaça de ruptura da coesão social. $^{23}$

Na perspectiva de Gramsci (2000), sem perder de vista sua concepção ampliada de Estado $^{24}$, podemos identificar a histórica relação das "reformas" na educação com o contexto econômico e político em seu conceito de Estado educador:

Tarefa educativa e formativa do Estado, cujo fim é sempre criar novos e mais elevados tipos de civilização, de adequar a "civilização" e a moralidade das amplas massas populares às necessidades do contínuo desenvolvimento do aparelho econômico de produção e, portanto, de elaborar também fisicamente tipos novos de humanidade (GRAMSCI, 
2000, p.23).

A "tarefa educativa e formativa do Estado", em Gramsci, está relacionada ao seu conceito de bloco histórico - unidade entre o estrutural e o superestrutural ou unidade entre o material (a base econômica) e o ético-político (dimensão política e ideológica). Nesse sentido,

[...] precisamente, as forças materiais são o conteúdo e as ideologias são a forma, distinção entre forma e conteúdo puramente didática, já que as forças materiais não seriam historicamente concebíveis sem forma e as ideologias seriam fantasias individuais sem as forças materiais (GRAMSCI, 1999, p. 238; grifo nosso).

Hoje, a tarefa educativa e formativa do Estado está pautada sob as premissas de "desenvolvimento sustentável" - no tripé: prosperidade econômica, qualidade ambiental e justiça social, mantendo a visão de educação como insumo econômico e mecanismo de enfrentamento da "questão social". Integra as concepções de capital humano e de capital social - qualificar o trabalhador de novo tipo em conformidade com as novas exigências do mercado, tendo em vista elevar a produtividade, e educá-lo para enfrentar as intempéries do mundo de trabalho mundializado.

Como elabora Marx (2002), n’O Capital - "lei geral da acumulação do capital” -, a própria dinâmica de reprodução ampliada do capital pode alterar circunstancialmente seu funcionamento, tendo em vista que ocorre em dois movimentos simultâneos: 1) absorvendo setores ainda não capitalizados, gerando um crescente assalariamento da força de trabalho disponível; 2) introduzindo incessantemente inovações tecnológicas, com isso, recriando, permanentemente, o desemprego e a "ociosidade forçada" ${ }^{25}$

Considerando que o ato de investir no social e em educação por parte dos empresários imprime as tensões desses dois movimentos, insere a concepção econômica da educação (nas perspectivas de investir no capital humano e social) e que se realiza, predominantemente, nas redes públicas de educação básica e nas camadas mais pobres da população, presumimos que o foco está em dois segmentos da "superpopulação relativa" (MARX, 2002, p.714) ${ }^{26}$ : na população "latente" - jovens e trabalhadores de setores tradicionais (rurais) aguardando oportunidade para ingressar nos setores modernos - e na população "estagnada" - parte da força de trabalho ocupada em funções precarizadas; "trabalhadores ativos com ocupações irregulares e eventuais" (Idem, p.746). O que caracteriza a relação da educação escolar com a "questão social".

No âmbito das recentes políticas públicas da educação brasileira, podemos identificar expressões da noção de investimento social privado - empreender ações inovadoras voltadas aos problemas sociais, por meio de rede social colaborativa e de forma a gerar resultados imediatos - e da "nova cultura organizacional" no Plano de Desenvolvimento da Educação (PDE). ${ }^{27}$

O PDE incorporou as metas e estratégias de "gestão de qualidade" do grupo de empresários e banqueiros brasileiros organizados no movimento Todos pela Educação (TPE). No âmbito das redes escolares públicas de ensino básico, destacamos duas medidas vinculadas a esta "união pessoal": a assinatura de cada unidade escolar no "termo de adesão voluntária" ao Plano de Metas Compromisso Todos pela Educação e sua adesão ao Plano de Ações Articuladas (PAR) - composto de "diagnóstico da educação básica do sistema local", "elaboração de instrumentos de Planejamento Estratégico", entre outras medidas de gerenciamento - como condição para a obtenção do "apoio suplementar e 
voluntário da União" (Decreto no 6.094/2007).

Desde então, constatamos a ocupação de membros do TPE: em Secretarias e em Conselhos de Educação; participando ativamente nas Conferências Nacionais de Educação (CONAEs, 2010 e 2014) e no Fórum Nacional de Educação, ambos criados pelo MEC, com a finalidade de elaborar o Sistema Nacional Articulado de Educação e o Plano Nacional de Educação 2011-2020; em Comissões para definição de política pública de responsabilização na educação e de regimes de colaboração (arranjos de desenvolvimento da educação), entre outros; ${ }^{28}$ presença constante nas mídias de massa como especialistas da educação; ocupação de secretarias de educação em redes municipais e estaduais; representando a educação brasileira em organismos internacionais. ${ }^{29}$ Como também em parceria com os inúmeros Programas do MEC: Programa Brasil Escolarizado, Programa Qualidade na Escola e Programa Brasil Alfabetizado e Educação de Jovens e Adultos e outros programas e projetos, no escopo de cada Secretaria - Secretarias de Educação Básica, ${ }^{30}$ Secretaria de Educação Continuada, Alfabetização, Diversidade e Inclusão ${ }^{31}$ e Secretaria de Educação Profissional e Tecnológica. ${ }^{32}$ Os Programas, Projetos e Ações desenvolvidos no âmbito MEC entrelaçam com outros Ministérios ${ }^{33}$ marcando a diretriz de atuar no enfrentamento da "questão social" dentro do tripé: educação, alívio à pobreza e trabalho e geração de renda.

Constata-se, também, que esse grupo organizado de empresários segue à luz dos "reformadores" empresariais da educação nos Estados Unidos, por meio do Programa No Child Left Behind (Nenhuma criança deixada para trás). Um programa que insere a abordagem neotecnicista e gerencialista empresarial nas escolas públicas estadunidenses. Segundo Freitas (2012), um neotecnicismo que "se estrutura em torno a três grandes categorias: responsabilização, meritocracia e privatização" (p. 383). Centralizado em testes padronizados que enfatizam os "processos de gerenciamento da força de trabalho da escola (controle pelo processo, bônus e punições), ancorada nas mesmas concepções oriundas da psicologia behaviorista" (Idem), incluindo elementos da "econometria, ciências da informação e de sistemas" (ibidem). E um gerencialismo que:

[...] reflete uma coalizão entre políticos, mídia, empresários, empresas educacionais, institutos e fundações privadas e pesquisadores alinhados com a ideia de que o modo de organizar a iniciativa privada é uma proposta mais adequada para "consertar" a educação americana, do que as propostas feitas pelos educadores profissionais (FREITAS, 2012, p. $380)$.

No Brasil, é crescente a expansão em nível nacional das parcerias público privadas com entidades que compõem o TPE, a exemplo da Fundação Roberto Marinho e o Instituto Ayrton Senna. Ambos desenvolvem projetos nos moldes neotecnicista estadunidense, com metodologias ditas inovadoras, denominadas de tecnologias sociais, voltadas para a "aceleração da aprendizagem" e para "corrigir a distorção idade-série". Prática incorporada no Plano Nacional da Educação - 2011-2020, a exemplo da meta 7.12 que incentiva práticas pedagógicas inovadoras, e sugerida pelo Banco Mundial como prática inovadora e exemplar em seus relatórios sobre as Estratégias da Educação 2020. ${ }^{34}$ Tais projetos impõem um padrão de avaliação, de conteúdo e de metodologia que confere um processo de expropriação do trabalho docente e indica o desmonte da educação pública, dada a ênfase no material pedagógico e metodologia dessas instituições. E abre, por outro lado, um nicho de mercado para consultores, empresas de organização de eventos, de venda de computadores, editoras, entre outros produtos como software, apostilas padronizadas, 
livros e jogos didáticos...

Freitas (2011), fazendo referência à Lei estadunidense No Child Left Behind ("Nenhuma Criança Deixada para Trás"), alerta que:

[...] as primeiras evidências da aplicação desta lei já a configuravam como um "cavalo de tróia" destinado a destruir o sistema escolar público. Afirmavam com clareza que a Lei não conseguiria cumprir esta promessa e que a ênfase desmedida nos testes como instrumento de controle das escolas iria produzir um estreitamento curricular nas disciplinas objeto de testagem e produzir um efeito contrário causando um declínio na qualidade de ensino. Em especial para as escolas que atendem crianças mais pobres, a educação seria mais limitada em seu currículo e em seu ensino. As escolas, ao final, se sentiriam menos responsabilizadas pela qualidade (p. 1).

Ressaltamos a direção político pedagógica em determinados Programas do MEC, a exemplo do PRONATEC (sob a direção do Sistema S) e do PRONACAMPO (sob a direção das empresas do agronegócio. Grande parte dos recursos públicos destinados a esses programas é para o setor privado. No caso específico do PRONATEC - criado em 2011 [por meio da Lei 1.513/2011] com o objetivo de "ampliar as oportunidades educacionais e de formação profissional qualificada aos jovens, trabalhadores e beneficiários de programas de transferência de renda - os cursos "são ofertados de forma gratuita por instituições da Rede Federal de Educação Profissional, Científica e Tecnológica e das redes estaduais, distritais e municipais de educação profissional e tecnológica", e também pelo Sistema S - SENAI, SENAC, SENAR, etc. Entre 2011 e 2014 foram 8 milhões de matrículas. Sendo que 70\% em cursos de FIC (formação inicial continuada) - cursos de curta duração e voltados para o trabalho simples - e $30 \%$ em cursos técnicos. Os cursos de FIC são, geralmente, ofertados pelo Sistema S. Pesquisando no Portal da Transparência do governo federal, até junho de 2015, dos mais de $\mathrm{R} \$ 551$ milhões do Orçamento da União executados para o PRONATEC, R \$518 milhões foram para o Sistema S. Em 2014, dos $\mathrm{R} \$ 2.648$ bilhões para o PRONATEC, R $\$ 2.581$ bilhões foram para o Sistema S.

E ainda, dentro do crescente número de Organizações Sociais (OS), ${ }^{35}$ a tendência de criação de escolas públicas administradas por empresas privadas. ${ }^{36}$ Essas escolas são apresentadas como modelos de educação profissional em tempo integral, com professores concursados selecionados para a proposta (flexibilização do plano de carreira na rede, por meio de gratificações por desempenho), professores contratados especificamente para a proposta (com "quebra da estabilidade de trabalho do professor" FREITAS, 2012, p. 395), com infraestrutura que destoa da grande parte das escolas da rede (salas de aula com equipamentos tecnológicos, laboratórios digitais, biblioteca, refeitórios, etc). ${ }^{37}$ Nesta configuração de parcerias público privadas, todas as escolas realizam processo seletivo para matrícula: expressão da meritocracia e do esvaziamento do sentido público da educação, na perspectiva das charters estadunidense, e do darwinismo social - seleção dos mais capazes para compor a força produtiva necessária às empresas parceiras.

Cabe destacar que essa política que até então se realizava por meio de parcerias com empresas em determinadas unidades escolares, tende a abranger toda a rede pública, como vem ocorrendo em Goiás. $\mathrm{O}$ atual governo abriu seleção pública para empresas configuradas como entidades privadas sem finalidade lucrativa, devidamente qualificadas no Estado de Goiás como Organização Social de Educação (OSE), nos termos do art. $6^{\circ}$-G 
da Lei Estadual $\mathrm{n}^{\mathrm{o}}$ 15.503, de 28 de dezembro de 2005, para administrar toda a rede pública de ensino.

No seu conjunto, as recentes políticas públicas de educação indicam um processo de "contrarreforma" (COUTINHO, 2012) ${ }^{38}$ em curso, exprime a articulação das relações de dominação interna e externa sobre o trabalho e a massa da população que, permanentemente, são destituídas de direitos econômicos, políticos e sociais básicos. Como analisou Fernandes (1981), trata-se do tipo de capitalismo, "selvagem", que opera a "sobre-exploração" e "sobre-expropriação" subordinadas e duplamente dominadas, conjugando crescimento econômico dependente com miséria e exclusão despótica, além de ausência de direitos.

\section{Considerações finais:}

Consideramos que nas condições históricas da atualidade torna-se fundamental apreender os mecanismos de consenso e de coerção que engendram mudanças na função social da educação pública básica, apreendendo a base conceitual dos contrarreformadores empresariais na educação. Isso requer averiguar as forças sociais que disputam as definições de políticas públicas educacionais em curso e identificar a natureza e o alcance dos programas e projetos pedagógicos implementados pelo setor empresarial nas redes públicas de ensino como investimento social privado.

Nas aproximações realizadas, vimos que a educação é a área prioritária dos investidores sociais privados. Conteúdo e forma - no qual conteúdo econômico-social e forma ético-política se identificam concretamente na consolidação de um bloco histórico na velha e decadente tradição da matriz liberal utilitarista e pragmática. A nosso ver, em conjunto, essas iniciativas significam ações articuladas do capital em prol do desmonte do caráter público da educação. Uma contrarreforma na educação brasileira operada pelo Estado, o Estado educador, voltada para "civilizar" as massas, assimilando-as ao nível cultural e econômico empresarial, que cria condições de governabilidade e de reprodução ampliada do capital, ao mesmo tempo em que busca ressignificar o caráter público da educação como direito social.

A inserção do empresariado na direção político pedagógico das escolas públicas brasileiras, diante desse bloco no poder - fortemente organizado por meio do Todos pela Educação e explícita "união pessoal" - é um grande desafio para a classe trabalhadora e para os trabalhadores da educação, pois o investimento social privado em educação insere a tarefa formativa e educativa na forma do empreendedorismo e da inovação, sem alterar seu conteúdo, extrair mais valor, com isso, sem alterar "as condições estruturais mínimas e à forma residual do "modo de ser burguês"' num país de capitalismo dependente (FERNANDES, 1973, p.69).

Diante dessa condição histórica que imprime um tipo de capitalismo periférico dependente, compondo uma "burguesia autocrática" (FERNANDES, 1981), para obter resultados desse "investimento" é imprescindível fazer uso de mecanismo que levem ao desmonte educação pública, que implica curvar a seus pés a força política dos profissionais de educação e expropriar o trabalho docente por meio de mecanismos coercitivos de controle social, de precarização das condições de trabalho e pela mercantilização da educação.

Nesse sentido, não podemos cair nessa armadilha neofilantrópica mercantil. E tornase primordial buscar compreender o que está posto, no âmbito do processo de hegemonia, com a recente configuração da "união pessoal", onde várias frações da classe dominante se unificam organizadamente no âmbito da sociedade civil e exercem funções explícitas de 
direção no âmbito da sociedade política, no tocante a definição de políticas públicas de educação, a fim de encontrar mecanismos de resistência.

\section{Referências:}

DEBONI, Fábio (Org.). Investimento Social Privado no Brasil: tendências, desafios e potencialidades. Brasília: Instituto Sabin, 2013.

COLEMARX - ADUFRJ. Plano Nacional de Educação 2011-2020: notas críticas. Rio de Janeiro: ADUFRJ, 2014. Disponível: http://www.adufrj.org.br/images/Plano $\% 20$ Nacional\%20de\%20Educa\%C3\%A7\%C3\%A3o.pdf. Acesso: 12/08/2014.

COUTINHO, Carlos Nelson. A época neoliberal: revolução passiva ou contra-reforma?

FERNANDES, Florestan. Sociedade de classes e subdesenvolvimento. $4^{\mathrm{a}}$ ed. Zahar, 1981. Novo Rumos, Marília, v. 49, n.1, p. 117-126, Jan-Jun, 2012.

FERNANDES, Florestan. Capitalismo dependente e classes sociais na América Latina. Rio de Janeiro: Zahar, 1973.

FREITAS, Luiz Carlos. Os reformadores empresariais da educação: da desmoralização do magistério à destruição do sistema público de educação. Dossiê: Políticas Públicas de Responsabilização na Educação. Revista Educação \& Sociedade. CEDES. São Paulo: Cortez; Campinas, CEDES. Volume 33, n. 119, abr/jun, 2012 (p. 379- 404).

GIFE. Guia Gife de Investimento Social Privado: Como Iniciar um Programa de Ação Social na sua Empresa, São Paulo: Gife, 2002.

GIFE. Guia Gife: Investimento Social Privado na Educação. São Paulo: Gife, 2003.

GIFE. Censo Gife 2009. São Paulo: Gife, 2009.

GRAMSCI, A. Cadernos do Cárcere. V.1. Introdução ao estudo da filosofia, a filosofia de Benedetto Croce. Rio de Janeiro/RJ: Civilização Brasileira, 1999.

INSTITUTO ETHOS de Empresas e Responsabilidade Social (Org). Diálogo empresarial sobre os princípios do Global Compact. São Paulo: Instituto Ethos, 2002.

KON, Anita. Responsabilidade social das empresas como instrumento para o desenvolvimento: a função da política pública. In: Planejamento e Políticas Públicas. Brasília: IPEA, n. 41, jul/dez, 2013 (p. 45-88).

LÊNIN, Vladimir I. O Imperialismo: forma superior do capitalismo. $3^{\text {a }}$ edição. São Paulo: Centauro, 2005.

MARX, Karl. O Capital: crítica da economia política. Livro 1, volume 2. $18^{a}$ edição. Rio de Janeiro/RJ: Civilização Brasileira, 2002.

MONTEIRO, Helena; KISIL, Marcos; WOODS, Márcia Kalvon (orgs). Tendencias de la inversión social privada en latinoamérica. São Paulo: Imprensa Oficial do Estado S/A; IDIS (Instituto para o Desenvolvimento do Investimento Social), 2011.

MOTTA, Vânia C. Ideologia o capital social: Atribuindo uma face mais humana ao capital. Rio de Janeiro: EDUERJ/FAPERJ, 2012.

NOGUEIRA, Fernando do A. e SCHOMMER, Paula Chies. Quinze Anos de Investimento 
Social Privado no Brasil: Conceito e Práticas em Construção. In: Anais do XXXIII Encontro da ANPAD. São Paulo/SP, 19 a 23 de setembro de 2009. Disponível: www.doar.org.br/biblioteca/artigos/isp_fernando_nogueira.pdf. Acesso: 23/11/2013.

ONU. Pacto Global Rede Brasileira. Implantando o Pacto Global das Nações Unidas Recomendações e primeiros passos. Disponível: http://www.pactoglobal.org.br/ Public/upload/ckfinder/files/Publicacoes/Primeiros_Passos_do_Pacto_Global.pdf. Acesso: 15/02/2013.

SCHUMPETER, J. A. Teoria do desenvolvimento econômico. São Paulo: Abril Cultural, 1982.

\section{Notas}

${ }^{1}$ Projeto científico: Educação na rota do desenvolvimento: investimento social privado em educação nos arranjos de desenvolvimento da educação. Chamada Universal- MCTI/CNPq No 14/2014.

${ }^{2}$ Lei n ${ }^{\circ} 11.079$, de 30 de novembro de 2004.

${ }^{3}$ As aspas na palavra "reforma", que serão aplicadas neste trabalho, visam ressaltar que, historicamente, as políticas públicas brasileiras, bem como as mudanças no âmbito da educação, possuíram tanto elementos de reforma - avanços dentro da ordem -, como de contrarreforma - retrocessos no tocante às conquistas da classe trabalhadora; na educação, em especial, em seu princípio de direito social.

${ }^{4}$ Plano Diretor da Reforma do Aparelho do Estado (1995).

${ }^{5}$ Leis $\mathrm{n}^{\circ}$ 9.637/1998 e n $\mathrm{n}^{\circ}$ 9.790/1999.

${ }^{6}$ A expressão questão social surge no século XIX, a partir da preocupação de um determinado setor da sociedade sobre o risco ou a "ameaça de fratura" das instituições sociais existentes, tendo em vista a acentuada e generalizada pobreza dos trabalhadores das primeiras concentrações industriais e de seu ingresso no cenário político. Sendo uma expressão conservadora, mas dado suas várias expressões (pauperismo, desemprego, precarização do trabalho...) e o caráter de poder, pesquisadores sociais críticos passam a utilizar a expressão questão social entre aspas. Sobre o debate ver: IAMAMOTO, Marilda V. A questão social no capitalismo. Revista Temporalis - Associação Brasileira de Ensino e Pesquisa em Serviço Social. Ano II, $\mathrm{n}^{\circ}$ 3, $2^{\mathrm{a}}$ edição. Brasília:ABEPSS, 2004 (p.09-32). NETTO, José Paulo. Cinco Notas a Propósito da 'Questão Social'. Revista Temporalis - Associação Brasileira de Ensino e Pesquisa em Serviço Social. Ano II, $n^{\circ} 3,2^{a}$ edição. Brasília/DF: ABEPSS, 2004 (pp.41-50).

${ }^{7}$ Trata da aprovação da proposta de criação dos arranjos de desenvolvimento da educação (ADEs).

${ }^{8}$ Banco Internacional de Reconstrução e Desenvolvimento (BIRD) [o qual integra o Banco Mundial], Banco Interamericano de Desenvolvimento (BID), Organização das Nações Unidas (ONU) e suas unidades: Organização das Nações Unidas para a Educação, Ciência e Cultura (UNESCO) e Comissão Econômica para a América Latina e Caribe (CEPAL).

${ }^{9}$ Ver: www.pactoglobal.org.br.

${ }^{10}$ Ver: GIDDENS, Anthony. A terceira via e seus críticos. Rio de Janeiro/RJ: Record, 2001 e A terceira via: reflexões sobre o impasse político atual e o futuro da social-democracia. $5^{\mathrm{a}}$ Ed. Rio de Janeiro/RJ: Record, 2005.

11 Pensador liberal clássico austríaco que considera o empresário o fenômeno fundamental do desenvolvimento econômico.

${ }^{12}$ No entanto, a expressão investimento social privado já tinha sido usada pelo Grupo, provavelmente pela primeira, em 2002, como veremos adiante.

${ }^{13}$ Jeffrey Sachs é economista norte-americano e foi diretor da ONU, coordenando o Programa Objetivos do Desenvolvimento do Milênio.

${ }^{14}$ PNUD. Desencadeando o empreendedorismo: o poder das empresas a serviço dos pobres. Relatório para o Secretário Geral das Nações Unidas. Comissão para o Setor Privado \& Desenvolvimento. New York, NY (USA), $1^{\circ}$ de março de 2004. PNUD. Criando valores para todos: estratégias para fazer negócios com os 
pobres. New York, NY (USA): ONU: Iniciativa Desenvolvendo Mercados Inclusivos, julho de 2008.

${ }^{15}$ Em entrevista recente para o GIFE, Jeffrey Sachs [diretor do Instituto Terra e Assessor Especial do Secretário-Geral da ONU, Ban Ki-moon], destaca a importância do investimento social privado para o desenvolvimento sustentável, tendo em vista que: "Vivemos um paradoxo, pois o know how tecnológico que pode solucionar problemas como a pobreza é também uma ameaça (....). Disponível: http://congressogife.org.br/2014/blog/o-investimento-social-e-uma-ferramenta-para-alcancarmos-o-

desenvolvimento-sustentavel-entrevista-com-jeffrey-sachs-assessor-especial-do-secretario-geral-da-onu/. Acesso: 04/09/2014.

16 Disponível: http://www.gife.org.br/artigo-investidores-sociais-querem-alinhar-recursos-para-educacao13500.asp. Acesso: 14/08/2009.

${ }^{17}$ Disponível: http://www.gife.org.br/arquivos/publicacoes/28/Censo\%20GIFE\%202011-2012.pdf Acesso: 02/06/2013.

${ }^{18}$ Conforme constata o Censo GIFE 2011/2012: “As empresas do setor financeiro e as fundações e institutos mantidos por elas representam mais de 54\% do total de recursos das organizações empresariais" (p. 30).

${ }^{19}$ Disponível: http://congressogife.org.br/2014/blog/saiba-como-foi-o-8o-congresso-gife/ 04/09/2014

${ }^{20}$ Compreendemos ideologia como concepção de mundo, cuja força material está na dinâmica de disputas e conservação da unidade ideológica em todo o bloco social (GRAMSCI, 1999, p.15).

${ }^{21}$ No decorrer do desenvolvimento da sociedade capitalista, a democratização do acesso à educação foi justificada, na perspectiva da burguesia, para formar o homem-cidadão, libertando-o das tradições acríticas e da fé impostas pelo antigo regime; como também para libertá-lo das condições de atraso e marginalidade impostas pela sociedade industrial ainda em formação, disciplinando a "classe laboriosa e perigosa" que começava a se organizar politicamente (Castel, 2003, Apud MOTTA, 2012, p. 253-255).

${ }^{22}$ No contexto da "guerra fria" a condução de orientação de políticas educacionais teve forte influência do Banco Mundial, gestão de McNamara, na perspectiva de alívio à pobreza, pois entendia que "a pobreza é a mãe do comunismo que destrói as liberdades e a democracia" (MOTTA, 2012, p.158). A "teoria do capital humano" de Schultz foi fundamental nessa conjuntura. Ver: SCHULTZ, T. O capital humano: investimentos em educação e pesquisa. Rio de Janeiro/RJ: Zahar, 1973. E sua crítica: FRIGOTTO, Gaudêncio. A Produtividade da Escola Improdutiva. $2^{\mathrm{a}}$ edição. São Paulo/SP: Cortez; Autores Associados, 1986 (Coleção Educação Contemporânea).

${ }^{23}$ Visão dos organismos internacionais no final dos anos 1990, em consequência do aprofundamento das mazelas sociais nos países de capitalismo dependente com as políticas neoliberais. Para o Banco Mundial, por exemplo: "a exclusão de grandes segmentos da sociedade desperdiça recursos potencialmente produtivos e gera conflito social" (BIRD, 2004. Apud. MOTTA, 2012, p. 135).

${ }^{24}$ Gramsci (1999) percebe que o Estado burguês, com seus aparelhos coercitivos e ideológicos, já não consegue impedir a formação voluntária de organismos de participação política ("aparelhos 'privados' de hegemonia"). E que no próprio interior dos aparelhos coercitivos e ideológicos do Estado - sistemas escolares e judiciários - existem disputas pela hegemonia - "...o Estado, ainda que os governantes digam o contrário, não tem uma concepção unitária e homogênea" (p.112), tendo em vista a disputa pela hegemonia que ocorre no âmbito da sociedade civil. Nesse sentido, aparelhos do Estado, sindicatos, organismos internacionais e entidades representantes de categorias diversas - os aparelhos "privados" de hegemonia dinamizam esse processo de hegemonia.

${ }^{25}$ Marx faz referência à "condenação de uma parte da classe trabalhadora à ociosidade forçada, em virtude do trabalho excessivo da outra parte", importante "para a formação da superpopulação relativa" (MARX, 2002, p. 738-739).

26 "A superpopulação relativa existe sob os mais variados matizes. Todo trabalhador dela faz parte durante o tempo em que está desempregado ou parcialmente empregado" (MARX, 2002, p.743).

${ }^{27}$ O PDE foi criado pelo Ministério da Educação (MEC) - Decreto n ${ }^{\circ} 6.094 / 2007$, que dispõe sobre o Plano de Metas Compromisso Todos pela Educação.

${ }^{28}$ Para uma análise sobre essa condução ver: Educação \& Sociedade: revista de Ciências da Educação. Centro de Estudos Educação e Sociedade. Desafios à Educação Brasileira: PNE, Responsabilização, Colaboração e Sistema Nacional de Educação. São Paulo: Cortez; Campinas, CEDES. Volume 34, n. 124, p. 641-646, jul/set, 2013; Educação \& Sociedade: revista de Ciências da Educação. Centro de Estudos Educação e Sociedade. Dossiê: Políticas Públicas de Responsabilização na Educação. São Paulo: Cortez; 
Campinas, CEDES. Volume 33, n. 119, p. 325-672, abr/jun, 2012.

${ }^{29}$ Em 2012, Viviane Senna, Presidente do Instituto Ayrton Senna, foi convidada pela Organização para Cooperação do Desenvolvimento Econômico (OCDE) para compor a rede NetFWD - "fórum internacional que reúne [...] institutos e fundações capazes de inspirar propostas inovadoras para a atuação social privada [...]. o Instituto Ayrton Senna, única organização brasileira participante do grupo fundador, foi convidado por sua atuação e produção de conhecimento na área da educação". Disponível: http://pt.wikipedia.org/wiki/Instituto_Ayrton_Senna. Acesso: 12/05/2014. Neste ano, a ex-Secretária de Educação Municipal do Rio de Janeiro, Cláudia Costin assumiu a pasta de Educação do Banco Mundial. Disponível: http://oglobo.globo.com/rio/paes-confirma-saida-de-claudia-costin-da-secretaria-de-educacao 1924489. Acesso: 20/03/2014.

${ }^{30}$ Pacto Nacional pelo Fortalecimento do Ensino Médio; Pacto Nacional pela Alfabetização na Idade Certa; Mais Educação; Ensino Médio Inovador; ProInfância; Saúde na Escola; Atleta na Escola; Formação continuada para professores; Livros e materiais para escolas, estudantes e professores; Tecnologia a serviço da Educação Básica; Apoio à Gestão Educacional; Infraestrutura; Avaliações da aprendizagem; Prêmios e competições; TV Escola.

${ }^{31}$ Diretoria de Políticas de Educação Especial - DPEE: Programa Escola Acessível; Transporte Escolar Acessível; Salas de Recursos Multifuncionais; Formação Continuada de Professores na Educação Especial; BPC na Escola (Benefício da Prestação Continuada da Assistência Social); Acessibilidade à Educação Superior; Educação Inclusiva: direito à diversidade; Livro Acessível; Prolibras; Centro de Formação e Recursos [CAP - Centro de Apoio para Atendimento às Pessoas com Deficiência Visual; CAS - Centros de Capacitação de Profissionais da Educação e de Atendimento às Pessoas com Surdez; NAAHS - Núcleos de Atividades de Altas Habilidades/Superdotação]. Diretoria de Políticas de Educação do Campo, Indígena e para as Relações Étnico-raciais: PRONACAMPO - Programa Nacional de Educação do Campo; PROLIND - Apoio à Formação Superior e Licenciaturas Interculturais Indígenas; Programa de Educação Tutorial (PET) Conexões de Saberes; UNIAFRO - Ações Afirmativas para a População Negra na Educação Superior; Formação Continuada de Professores em Educação Quilombola e para as Relações Etnico-Raciais; Educação Quilombola; Educação Escolar Indígena; Formação Continuada de Professores em Educação Escolar Indígena. Diretoria de Políticas de Educação em Direitos Humanos e Cidadania: Acompanhamento da Frequência Escolar de Crianças e Jovens em Vulnerabilidade - Condicionalidade em Educação do Programa Bolsa Família - PBF; Formação Continuada de Professores e Gestores em Educação Ambiental e Educação em Direitos Humanos; Projeto Escola Que Protege; entre outras ações. Diretoria de Políticas de Alfabetização e Educação de Jovens e Adultos - DPAEJA: PBA - Programa Brasil Alfabetizado; PNLDEJA - Programa Nacional do Livro Didático para a Alfabetização de Jovens e Adultos; Concurso Literatura Para Todos; Educação em Prisões; Medalha Paulo Freire. Diretoria de Políticas Educacionais para a Juventude: Projovem Urbano.

${ }^{32}$ Programa Mulheres Mil; Programa Nacional de Acesso ao Ensino Técnico e ao Emprego (Pronatec); Rede Certific; Programa de Expansão da Rede Federal de Educação Profissional; Programa Brasil Profissionalizado; Rede e-Tec Brasil; Programa Nacional de Integração da Educação Profissional com a Educação Básica na Modalidade de Educação de Jovens e Adultos (Proeja); Curso Técnico de Formação para os Funcionários da Educação (Profuncionário)

${ }^{33}$ Sendo os principais: Ministério do Trabalho e Emprego (MTE) [Projovem Trabalhador]; Ministério do Desenvolvimento Social e Combate à Fome (MDS) [Programa Brasil sem Miséria, Bolsa Família, Sistema Nacional de Segurança Alimentar e Nutrição (SESAN), Programa de Aquisição de Alimentos (PAA), Sistema Agroalimentares Locais (SISAN), Fomento à Produção e à Estruturação Produtiva, entre outros, inclusive de Assistência Social); Ministério de Ciência e Tecnologia (MCTI) [que inclui em sua quarta ação Ciência, Tecnologia e Inovação para o Desenvolvimento Social - a popularização da ciência, tecnologia e informação (CT\&I) para a melhoria do ensino e o desenvolvimento de tecnologias para o desenvolvimento social - tecnologias sociais. Esta última "atua em temas e áreas diretamente ligados à questão social, voltados mais especificamente, para a identificação e solução de demandas sociais locais relativas à geração de renda e ocupação, como por explo" http://www.mct.gov.br/index.php/content/view/78537/Atuacao.html].

34 BIRD-BANCO MUNDIAL. Atingindo uma educação de nível mundial no Brasil: próximos passos. Sumário executivo. Brasília, Brasil: Banco Mundial, 2010 (Disponível nos sites do MEC e do TPE: http://www.todospelaeducacao.org.br/biblioteca/1390/atingindo-uma-educacao-de-nivel-mundial-no-brasilproximos-passos---sumario-executivo/) e BIRD-BANCO MUNDIAL. Banco Mundial: consultas sobre a 
nova estratégia da educação 2020. [2011?]. (http://siteresources.worldbank.org/EDUCATION/ Resources/ESSU/Strategy_Powerpoint_BR.pdf).

${ }^{35}$ Organizações de direito privado, sem fins lucrativos, criadas por setores públicos a fim de repassar a administração de serviços antes exclusivos do Estado para o setor privado (Lei $n^{\circ}$ 9637/1998), principalmente nas áreas da saúde, cultura e educação-pesquisa. Segundo a Rede Gife estão cadastradas no Ministério da Justiça - Cadastro Nacional de Entidades de Utilidade Pública - 17.681 entidades, sendo que 3.963 são organizações da sociedade civil e 11.954 são entidades sociais de utilidade pública federal, 90 são organizações estrangeiras e 1.674 são associações ou fundações não tituladas ou qualificadas. Disponível: site.gife.org.br/artigo-acordo-abre-polemica-sobre-fiscalizacao-de-entidades. Acesso 23/08/2010.

${ }^{36}$ No Rio de Janeiro, por exemplo, existem colégios de ensino médio integral em parceria com empresas e organizações do terceiro setor: o Núcleo Avançado em Educação (Nave), funcionando no Colégio Estadual José Leite Lopes, na Tijuca, em parceria com a empresa Telemar (Oi); o Colégio Estadual Hebe Camargo, em Pedra de Guaratiba, Zona Oeste do Rio, em parceria com a Fundação Xuxa e Embratel; o Núcleo Avançado em Tecnologia de Alimentos (Nata), no Colégio Estadual Comendador Valentim dos Santos Diniz, em São Gonçalo, entre outros colégios. (ver: http://www.rj.gov.br/web/seeduc/ exibeconteudo?articleid=1770381; acesso: 05/09/2014).

${ }^{37}$ Conforme apontado no COLEMARX-ADUFRJ (2014): “....apenas 0,6\% das escolas brasileiras têm infraestrutura próxima ao padrão mínimo para escolarização: biblioteca, laboratório de informática, quadra esportiva, laboratório de ciências e dependências adequadas para atender estudantes com necessidades especiais e básicas, ou que $44 \%$ das instituições de educação básica contam apenas com água encanada, sanitário, energia elétrica, esgoto e cozinha em sua infraestrutura" (p. 26).

${ }^{38}$ Embora se apresente como "reforma", com isso insere elementos de absorção das demandas da classe trabalhadora, a política pública de educação em curso se caracteriza como "contrarreforma", uma vez que predominantemente apresenta elementos de "restauração". Ver: COUTINHO, 2012.

Recebido: $\quad$ março-16 Aprovado: setembro-16 